\title{
Automated Soil Nutrient Content Analysis and Fertilizer Suggestion for Farmers
}

\author{
M.K.Dharani, K.R.Prasanna Kumar
}

\begin{abstract}
In India agriculture and its practices plays the vital role, since more number of people are employed in that process. The agricultural process goes on with the sowing, maintenance and yield. The yield of the crop purely depends on the season, maintenance and the nutrient content available in the soil. Soil nutrient analysis has been made before sowing period with the help of soil testing laboratory, based on the laboratory results and the selected crops. End of the analysis process the fertilizer suggestion would be given to the farmer. In the existing system the analysis process is done manually and farmers would be given direct suggestion about the fertilizer. Since the process is repetitive it consumes more time and there may be chance of human error which may majorly affect the yield. The main aim of the proposed work is to design an Automated Fertilizer Suggestion (AFS) application to give effective suggestions to farmers about the fertilizers with respect to crops based on the soil test results. Our proposed application reduces the time, controls the human errors, avoids the over dumping of fertilizer in the soil and improves the yield.
\end{abstract}

Keywords: Nutrient, Analysis, Soil, Fertilizer, Agriculture, Soil nutrient analysis. Farmers, Testing

\section{INTRODUCTION}

Agriculture and its allied sectors provide the primary source of lively hood for around 58 percentage of Indian population. The back bone of the Indian economy and the strength lies in the agriculture. It contributes a significant figure to the country's GDP of around 18 percent. The system of agriculture followed is completely based on the horticulture with respect to the seasonal climatic condition. The conventional practice of farming involves the activities that human laborers performing all types of farming activities. It is completely based on the experience and the guidance given by their elders and ancestors. As the days goes on the advancement in the technology is moving the agriculture to the greater extent.

In the agriculture plant growth is mainly dependent on the health of the soil and the irrigation[1]. The soil nutrient decides the efficient crop yield. A proper soil test would help the farmer to ensure the amount of fertilizer required and the available nutrients in the soil. It would also allow to determine lime requirements and can be used to diagnose problem areas. The commonly measured nutrients in the soil are the Nitrogen $(\mathrm{N})$, Phosphorus $(\mathrm{P})$, Potassium $(\mathrm{K})$ and $\mathrm{pH}$ level. It is a useful information about the soil in the aspects of soil fertility and plant growth. Even though the nutrient of the

Revised Manuscript Received on November 25, 2019.

* Correspondence Author

M.K.Dharani, Department of Computer Science and Engineering,Kongu Engineering College, Perundurai, India. Email: mkdharanishka@gmail.com

K.R.Prasanna Kumar, Department of Computer Science and Engineering, Kongu Engineering College, Perundurai, India. Email: krprasanname@gmail.com. soil is very important and it takes the major part in plant growth and yield, the equal importance should be given to $\mathrm{pH}$ value of the soil.

\section{LITERATURE REVIEW}

DhareshVadalia [2] suggested a system to predict a suitable crops for the particular soil based on its soil type. In order to predict the soil type the soil nutrients such as Nitrogen, Potassium, Phosphorous has been taken. Based on the average value of the nutrients the soil type was segregated. The system was designed in such a way that to suggest the crops based on the real time nutrient values and the $\mathrm{pH}$ level of the soil.

Rohit Kumar Rajak [3] proposed a system with the machine learning techniques such as support vector machine and artificial neural network. The system was designed in such a way that to suggest a crop with the specific parameters. The dataset collected from the agriculture soil testing lab were used to train the system. The major soil nutrient parameters and soil type parameters were analyzed and then the expert's rules were also used in training system. The system provides a crop with the greater efficiency and accuracy.

Sonikajha[4] mentioned a framework where the electrochemical sensors were placed around the agricultural field. The sensor senses the value such as potassium, Nitrogen and Phosphorous based on which the fertilizer suggestion would be given. The suggestion would be site specific. In this techniques based on the sensed values the system will analyze the nutrient deficiency in each part of the land. Based on the nutrient deficiency the fertilizers were applied to that particular part of the land instead of applying it for the entire field. This system improved the crop yield to a higher extent and it reduces the dumping of fertilizer in the agricultural land.

Devika[5] characterizes the crop prediction based on the previous year's data. The agriculture dataset of Trichy district was taken and then and then the system was trained. The regression technique was used to analyze and predict the yield of the crop based on the available data in the data set. Based on the soil type and the seasonal crops and the percentage of yield were taken as input. The system were trained using the regression technique using Ecuadorian conditions. The linear regression uses the parameter such as year, area production and crop, climate and it will produce the crop suggestion with higher accuracy 


\section{Automated Soil Nutrient Content Analysis and Fertilizer Suggestion for Farmers}

\section{PROPOSED WORK}

The soil nutrient management is the necessary practice in agriculture. Recent years due to the huge growth of fertilizer industry farmers start to use the fertilizers to improve the yield. However the fertilizer may give the higher yield but also it will leave the side effects when used improperly or improper quantity. Whatever the fertilizer, quantity and how to use/apply it is the very important factor. Usually the farmer get the usage details from the co - farmers or the shop owner who sells the product. If the farmer goes on with co- farmers suggestions or fertilizer shop owners suggestion means it may spoil the yield due to improper usage or dose. So the farmer need to go for soil test and based on the test result have to choose the appropriate fertilizer and its dosage.

The soil testing center and the agriculture office is functioning in most of the thaluk in Tamilnadu. The farmers can test the soil and get fertilizer suggestion from the officials. Based on the soil testing result and the season the officials will suggest the fertilizer based on the nutrient requirement in soil and crops based on the season. In the present scenario the testing calculation and the fertilizer, crop suggestion was made by manually. It leads to more time consumption and sometimes leads to human error which makes the farmers to feel difficult. Also there is no digital system to maintain the farmer details. Mostly the records are maintained manually in the form of registers.

The AFS application contains the Nutrient Analysis Algorithm (NAA) which takes the soil test results as input and provides fertilizer suggestions as a result. AFS maintains all the farmer details uniquely along with their soil test values and nutrient suggestions in digital form. It mainly avoid replica of the farmer details, reduces the paper usage and time. The periodical monitoring of yield of a particular farmer can also be made easily.

\section{FUNCTIONALITY OF ASF}

The ASF consists of different modules. The Figure 1 gives a pictorial relationship among the ASF with farmer and officials. The official user is also named as admin.

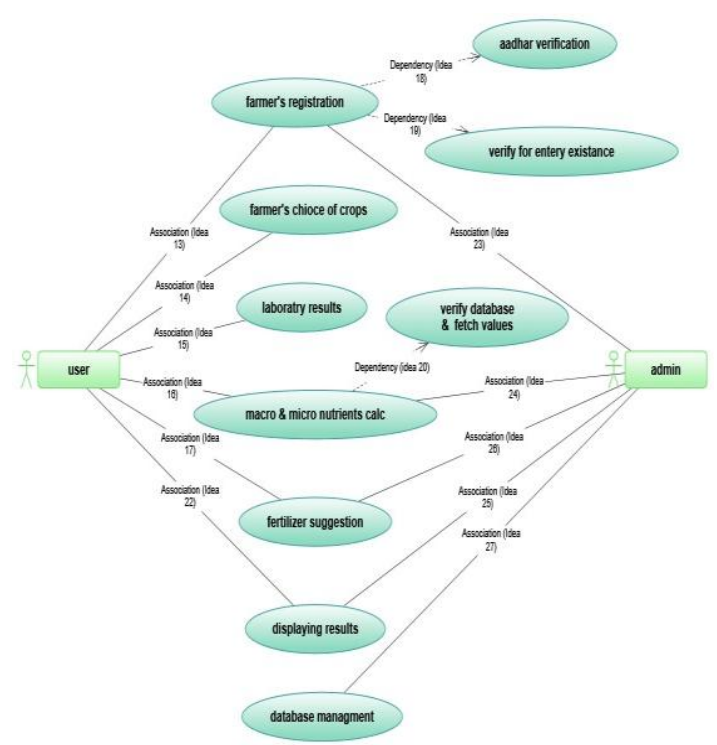

Fig. 1: ASF functional diagram

\section{A. Farmer profile management:}

Each farmer's record is uniquely maintained by using their Aadhar number or mobile number. So the farmer need to register in ASF only once. From the next time by providing mobile number or Aadhar number official can fetch their details and also previous soiltestdetails. The above procedures are done when the farmer brings the soil for testing.

\section{B. Soil type classification:}

The region of red loamy soil is chosen for analysis, the obtained soil would be sent to the laboratory for testing. Based on the appearance and the texture the soil is being further classified in to read loamy sandy and read loamy clay soil. The analysis part starts with the analysis of salt which can be achieved through the electrical conductivity test. The $\mathrm{pH}$ level analysis on the salt gives the measure of acidic and alkaline content of the soil. The $\mathrm{pH}$ value ranges from the 0 to 14. The optimal range of $\mathrm{pH}$ is 7 . When the $\mathrm{pH}$ value ranges between $0<=\mathrm{pH}>=6.9$ then it is acidic else if it is between $7.1<=\mathrm{pH}>=14$ then the soil is in alkaline nature. It is impossible to maintain a soil in a balanced $\mathrm{pH}$ value and cultivate. Generally the $\mathrm{pH}$ value with respect to crops ranges from 4.0 to 8.0. Normal red soil would have the $\mathrm{pH}$ value of range 5.5 to 7.5 . In the case of the maximum and the minimum deviation in $\mathrm{pH}$ value, nutrient analysis was made based on the given soil and then the fertilizer suggestion is given.

\section{Nutrient analysis process:}

The soil nutrients were broadly classified into macro and micro nutrients. In general macro nutrients of the soil include nitrogen, phosphorous, potassium, sulfur, calcium, magnesium. The nitrogen phosphorous and potassium are considered as the primary macro nutrient content. So the laboratory tests were made on the given soil to check the availability of the macro nutrients. In the normal soil the potassium level is of about $10,000 \mathrm{mg} / \mathrm{kg}$, phosphorous of about $2,000 \mathrm{mg} / \mathrm{kg}$ and nitrogen of about $15,000 \mathrm{mg} / \mathrm{kg}$. The laboratory test analysis would give the value of primary nutrient contents present in the given sample soil. The obtained titrated value is compared with the soil log value and then the available primary macro nutrient contents per acer would be calculated automatically by the ASF application.

\section{Algorithm: Nutrient Analysis Algorithm}

Variables:

N_ma: Macro nutrient titration value of nitrogen in $\mathrm{ml}$ P_ma: Macro nutrient titration value of phosphorous in $\mathrm{ml}$ K_ma: Macro nutrient titration value of potassium in $\mathrm{ml}$ N_ppm: Macro nutrient titration value of nitrogen in parts per million

P_ppm: Macro nutrient titration value of phosphorous in parts per million

K_ppm: Macro nutrient titration value of potassium in parts per million

$\mathrm{N}$ - Nitrogen present in the soil

$\mathrm{P}$ - phosphorous present in the soil

$\mathrm{K}$ - Potassium present in the soil

nlog, $n 1 \log$ - defined nitrogen log values

plog, p1log - defined phosphorous log values

klog, k1log - defined potassium log values 
n_a - actual level of nitrogen needed for particular crop

p_a - actual level of phosphorous needed for particular crop

$\mathrm{k} \_\mathrm{a}-$ actual level of potassium needed for particular crop

n_per_ac: nitrogen needed per acer

k_per_ac: potassium needed per acer

p_per_ac: phosphorous needed per acer

crop_id: Unique number for each crop

\section{Procedure:}

I*Mapping of macro nutrients to find the need of fertilizer*/

N_ppm $\leftarrow$ N_ma*1000;

P_ppm $\leftarrow$ P_ma* 1000 ;

K_ppm $\leftarrow$ K_ma* 1000 ;

If $($ crop $==\{$ crops in list $\})$

Then

Get the crop_id

If $($ N_ppm $==$ nlog[crop_id $])$

Then

$\mathrm{N} \leftarrow \mathrm{n} 1 \_\log$ [crop_id]

If $(\mathrm{N}==$ n_a[crop_id]

Then

Nitrogen normal level

Else

$\mathrm{N}=\mathrm{N}-\mathrm{n} \_\mathrm{a}$

n_per_ac $=\mathrm{N} * 14 * 2.5$

If $($ P_ppm $==$ plog[crop_id] $)$

Then

$\mathrm{P} \leftarrow \mathrm{p} 1 \log$ [crop_id]

If $\left(\mathrm{P}==\mathrm{p} \_\mathrm{a}\right.$ [crop_id]

Then

Phosphorous normal level Else

$\mathrm{P}=\mathrm{P}-\mathrm{p} \_\mathrm{a}$

p_per_ac $=\mathrm{P} * 1.66$

If $\left(\mathrm{K} \_\right.$ppm $\left.==\mathrm{k} \log \left[\mathrm{crop} \_\mathrm{id}\right]\right)$

Then

$\mathrm{K} \leftarrow \mathrm{k} 1 \log$ [crop_id]

If(K==k-a[crop_id]

Then

Potassium normal level

Else

$$
\begin{aligned}
& \mathrm{K}=\mathrm{K}-\mathrm{k} \_\mathrm{a} \\
& \mathrm{k} \_ \text {per_ac }=\mathrm{K} * 5
\end{aligned}
$$

\section{Fertilizer suggestion and data management:}

The obtained macro nutrient contents are compared with the default permiciple values of the nutrients in the database. If there is any change with the comparative values, then the needed level of nutrient content for the soil could be calculated. Based on the requirement of the nutrition content level the amount of fertilizer needed per acer would be calculated. The necessary fertilizer suggestions would be given to the farmers based on the seasonal crop, which the farmer prefers. The data predicted and analyzed would be stored with all the intermediate steps. The farmer and their field details would also be stored for the future reference. The data would be periodically verified and mentioned by the office administrator.

\section{RESULT AND DISCUSSION}

ASF application was tested in with around 2553 samples obtained from the soil testing unit in southern region of Tamil Nadu. These samples are taken from the soil nutrient analysis made for the year 2018. The obtained results from ASF application are validated with manual results which already done. Almost $90 \%$ samples matched with the same result as the manual calculation. But the $10 \%$ deviation was again cross validated and checked it was found that the variation was due to the human error. So the designed system completely rectifies the human error in fertilizer suggestion, reduces time and simplifies the record management.

\section{CONCLUSION}

The fertilizer suggestion based on the ASF application was made. The laboratory iteration values are obtained and fed into the system. Then the ASF compares the soil nutrient, $\mathrm{pH}$, and electrical conductivity of the soil with the normalized value and the available nutrients of the soil and the fertilizer suggestion is given as an end result to farmers. In this method the manual calculation is reduced and the fertilizer suggestion is made effectively to have a better yield.

In future, crop yield can be monitored a stored and then based on the yield the suggestions can be improved further with Machine Learning (ML) techniques. Where the entire data of the particular field in an agriculture sector are used to train the model. The trained system will work based on the complete knowledge and will definitely help the agriculture sector boom again and go ahead further.

\section{REFERENCES}

1. S. Sangeetha, M. K. Dharani, B. Gayathri Devi, R. Dhivya, P. Sathya Prediction of Crop and Intrusions Using WSN, Proceedings of 3rd International Conference on Advanced Computing, Networking and Informatics, vol:2, pp: 109-115, 2016

2. DhareshVadalia, MinalVaity, KrutikaTawate, DynaneshwarKapse, Real Time soil fertility analyzer and crop prediction, International Research Journal of Engineering and Technology (IRJET) Volume: 04 Issue: 03 ,Mar -2017.

3. Rohit Kumar Rajak, AnkitPawar, MitaleePendke, PoojaShinde, Suresh Rathod,AvinashDevare, Crop Recommendation System toMaximize Crop Yield using Machine Learning Technique, International Research Journal of Engineering and Technology (IRJET) Volume: 04 Issue: 12 ,Dec-2017.

4. Sonikajha and Suneetha V., Nutrient analysis of soil samples from various places, International Research Journal of Engineering and Technology (IRJET) Volume: 03 Issue: 9, Aug-2016

5. Devika, B.Aananthi, Analysis Of Crop Yield Prediction Using Datamining technique To Predict Annual Yield Of Major Crops,International Research Journal of Engineering and Technology (IRJET) Volume: 04 Issue: 10, Dec-2016

6. N. Hemageetha, Dr. G.M. Nasira, "Analysis of soil condition Based on $\mathrm{pH}$ value using Classification Technique", IOSR-JCE, Volume 18, Issue 6, Nov 16.

7. Leona, M.R.C., Jalaob, E.R.L.: A prediction model framework for crop yield prediction. In: Asia Pacific Industrial Engineering and Management System (2013)

8. https://soils.wisc.edu/facstaff/barak/soilscience326/macronut.htm

9. https://emeraldlawnsaustin.com/macronutrients-micronutrients-soil/

10. https://nrcca.cals.cornell.edu/soilFertilityCA/CA1/CA1_print.html

11. http://pss.uvm.edu/ppp/pubs/oh34.htm

12. .https://serc.carleton.edu/microbelife/research_methods/environ_sampli $\mathrm{ng} / \mathrm{pH}$ EC.htm

13. https://www.cropnutrition.com/efu-soil-p

\section{AUTHORS PROFILE}

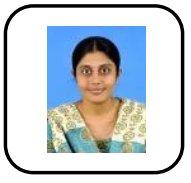

M.K.Dharani completed her BE (CSE) and ME (CSE) in Avinashilingam Institute forHome Science and Higher Education for Women. She is working as Assistant Professor in Department of Computer Science and Engineering, Kongu Engineering College. Her area of interest are IoT, Machine Learning. 


\section{Automated Soil Nutrient Content Analysis and Fertilizer Suggestion for Farmers}

K.R.Prasanna Kumar completed his BE (CSE) and $\mathrm{ME}$ (CSE) in Kongu Engineering College.He is pursuing his $\mathrm{PhD}$ in Cloud Computing. He is working as an Assistant Professor in Department of Information Technology, Kongu Engineering College. $\mathrm{He}$ is expertise in web designing and mobile application development. 